\title{
COMO REPENSAR O JORNALISMO A PARTIR DA PAUTA SOCIAL: REFLEXÕES SOBRE DESAFIOS DA COBERTURA DE POLÍTICAS PÚBLICAS SOCIAIS PELA MÍDIA
}

\author{
HOW TO RETHINK JOURNALISM FROM THE SOCIAL AGENDA: \\ REFLECTIONS ON THE CHALLENGES OF MEDIA COVERAGE OF SOCIAL \\ POLICIES
}

\author{
Marta Maia ${ }^{1}$ \\ Hila Rodrigues $^{2}$ \\ Ana Paola de M. Amorim Valente ${ }^{3}$
}

Recebido em 23/10/2011

Aceito em 06/12/2011

\section{RESUMO}

Este artigo pretende discutir as implicações da exclusão ou inclusão da pauta social na mídia. A despeito do que aconteceu com outras áreas do jornalismo que geraram especializações, como o jornalismo econômico e o político, a ampliação do espaço das políticas públicas sociais nas agendas públicas não se fez acompanhar pelo proporcional espaço nas coberturas diárias. Esta discussão apresenta uma série de questionamentos sobre o fazer jornalístico dentro de um contexto de reflexões sobre critérios que têm tradicionalmente orientado a produção jornalística. Pensar sobre o espaço da pauta social requer reflexões que, neste artigo, são feitas a partir de um diagnóstico da mídia impressa, mas que pode se estender para outros suportes, com potencial para questionar reformulações de critérios de seleção e hierarquização de notícias.

Palavras-chave: Jornalismo. Cobertura. Pauta social.

\begin{abstract}
This article intends to present to discuss the implications of exclusion or inclusion of the social agenda in the media. Despite what happened to other
\end{abstract}

\footnotetext{
${ }^{1}$ Doutora em Jornalismo - Ciências da Comunicação - pela Escola de Comunicações e Artes da Universidade de São Paulo (ECA/USP), mestre em Educação pela Universidade Metodista de Piracicaba e professora adjunta do curso de Jornalismo da Universidade Federal de Ouro Preto (UFOP). E-mail marta@ martamaia.pro.br

2 Jornalista, mestre em Administração Pública pela Escola de Governo da Fundação João Pinheiro (MG), doutora em Ciências Sociais pela Pontifícia Universidade Católica de Minas Gerais e professora adjunta do curso de Jornalismo da Universidade Federal de Ouro Preto. E-mail: hilarodrigues@hotmail.com

${ }^{3}$ Mestre em Ciência da Informação pela Universidade Federal de Minas Gerais (UFMG) e doutoranda em Ciência Política na UFMG, professora do curso de Jornalismo da Universidade Fumec. E-mail: <anapaola@fumec.br>
} 
areas of journalism that generated specializations, such as economic and political journalism, expanding the space of social policies in the public agenda has not been accompanied by proportional space in daily coverage. This observation, we believe, presents a series of questions about doing journalism within the context of reflections on criteria that have traditionally guided the journalistic production. Think about the space of the social agenda requires reflections that in this article are made from a diagnosis of printed media, but which may extend to other media, with the potential to question reformulations of selection criteria and ranking news.

Keywords: Journalism. Coverage. Social agenda.

Até hoje, início do século XXI, é comum ouvir generalizações como "o mercado necessita de jornalistas especializados em economia". Esta equação simples, que projeta demandas profissionais por meio de tendências de especialização, demonstra também que há uma hierarquia oculta nas redações: economia e política já se firmaram como editorias nobres. Se os noticiários econômicos e políticos são as pupilas da redação, a alma está nas ruas e isso não é exatamente uma novidade: já na abertura do século XX João do Rio praticou um jornalismo mais próximo do cotidiano do que o até então jornalismo de gabinete praticado nos jornais brasileiros. Qualquer debate sobre possibilidades de especialização no jornalismo, portanto, envolve a questão do processo de produção da informação em sua complexidade e, paradoxalmente, em sua singularidade. No caso deste artigo, pretende-se avaliar como o fazer jornalístico açambarca e/ou elimina a pauta social na mídia. Se a pauta social depende dos gabinetes oficiais para respostas das muitas demandas da sociedade, sua origem encontra-se na rua e isso leva a repensar os esquemas já cristalizados de cobertura. Exige um olhar atencioso para dentro das redações, sendo uma precondição para garantir, reforçar e, em alguns casos, restaurar, o espírito crítico aguçado da imprensa. Entender a realidade social sempre foi o grande desafio do jornalismo, embora nem sempre tão evidenciado como deveria.

Em seu processo de legitimação, o jornalismo se firma sobre as bases do gênero informativo. A separação entre notícia e opinião é o marco do jornalismo moderno e a primazia da primeira sobre a segunda não deixa de ser um avanço no sentido de enfatizar a qualidade informativa. Mas o processo de modernização e industrialização vai além e, também orientado pelo propósito de valorizar a informação, implica a organização em editorias como uma necessidade emergente de organizar os temas, notícias - uma necessidade inspirada na divisão do trabalho, no capitalismo, na industrialização que marca o início do século XX. Essa divisão faz parte das inovações na imprensa nesse período. Ela teria vindo com a tendência ao declínio do folhetim (substituído pelo colunismo e, em seguida, pela reportagem), com a emergência das entrevistas e o predomínio da chamada informação objetiva sobre a doutrinação. $\mathrm{O}$ que leva à substituição de textos de colaboradores por notícias, entrevistas, reportagens. Já no final da década de 1990, Nélson Werneck Sodré dizia que essa "divisão de matéria" está "intimamente ligada à tardia divisão do trabalho, que começa a impor as suas inexoráveis formas." (SODRÉ, 1999, p. 296-297). Nilson Lage recorre aos princípios (para a construção de um jornal) apregoados na década de 1950 por Jack S. Sissors, professor de jornalismo da Northwestern University, que diz: "categorize as notícias por títulos permanentes colocados no topo de cada página. Podem ser usados nomes de assuntos ou de áreas geográficas". (LAGE, 2001, p.17). Também Samuel Wainer, quando aborda os avanços do jornal Última Hora, no início da década de 1950, conta que agregou às "seções convencionais - política, economia, internacional, assuntos nacionais etc." o segundo caderno, com "esportes e divertimentos" (WAINER, 1988, p. 145). Estes exemplos mostram que a discussão sobre a conotação visual e de organização por conteúdo é uma constante no campo jornalístico; entretanto, é preciso evidenciar o papel do setor mercadológico das empresas na cadernalização dos jornais, que associam público, consumo e vendas. Como argumenta Cremilda Medina, é preciso considerar a 
informação jornalística como produto da comunicação de massa, comunicação de massa como indústria cultural e indústria cultural como fenômeno da sociedade urbana e industrializada (MEDINA, 1978, p. 20).

A especialização garante seu espaço então mais como estratégia de segmentação de públicos do que propriamente como aliado, por si, de qualidade do conteúdo. Assim, as especialidades se movimentam no mercado editorial mais ao sabor das marés econômicas do que propriamente informativas. A sucessão de planos econômicos valorizou a editoria de economia. Avanços tecnológicos deram aos jornais seções e revistas especializadas em informática, entre outros. Sobretudo a partir dos anos 1980, o neoliberalismo tentou expurgar a questão social das agendas públicas em nome de um Estado mais enxuto e ágil, voltado para a eficiência das estratégias de desenvolvimento econômico. (SANTOS, 2004; IPEA, 2005).

Nos últimos anos, contudo, percebe-se o caminho inverso e as políticas sociais conquistam um espaço importante. É objeto de fóruns internacionais, sendo incluídas, em encontros de cúpula, sessões específicas para discutir questões relacionadas à pobreza, agricultura familiar, desigualdade social, entre outras. Exemplo disto é a incorporação do tema no Mercosul, durante a $36^{a}$ Reunião Ordinária do seu Conselho de Estados Partes e Associados, realizada no final de 2008, e que produziu dois documentos importantes para a área: o Plano Estratégico de Ação Social do Mercosul e a Declaração Sobre Medidas de Promoção e Proteção na Área Social em Resposta à Crise Financeira Mundial. No mesmo encontro, foi aprovado um orçamento de US\$ 227 mil para criação do Instituto Social do Mercosul. No Brasil, desde o embrião plantado pelos movimentos sociais na Constituição de 1988, o tema ganha centralidade a partir de 2003 de maneira pioneira em nossa história, dando às políticas sociais um status que não tinham. Mas, ao contrário do que aconteceu em outras áreas, não se percebe nos mercados das redações um esforço objetivo de promover a especialização dos profissionais para cobertura das políticas públicas em área tão específica, a despeito da centralidade que o tema começa a assumir nas agendas governamentais e públicas. Isto pode ser mais uma confirmação de que a segmentação se orienta mais por critérios mercadológicos do que jornalísticos. Ao mesmo tempo, sabe-se que não é só o mercado que determina, mesmo porque nenhum jornal pode ignorar movimentações importantes na sociedade. O leitor sente a ausência de determinados assuntos. O que ocorre, entretanto, na maioria das vezes, é que a cobertura da pauta social até abarca certos assuntos, mas estes acabam sendo tratados sob o enfoque econômico, por exemplo, desconsiderando outros possíveis olhares.

Um exemplo disto é o fato de que o Brasil vive um período de crescente mobilização social, com aumento do número de conferências nacionais sobre políticas públicas de várias áreas - saúde, educação, assistência social, mulheres etc. - e esses eventos não encontram repercussão na mídia, ainda que reúnam em média mais de 1.500 pessoas $^{4}$.

É até possível, sob este prisma, que a pauta social quase não apareça nas páginas noticiosas em razão do desconhecimento daqueles que produzem a notícia-desconhecimento das nuances que permeiam os conceitos de 'política pública' e 'política social'. Afinal, "vender" uma pauta social em uma redação exigiria, em primeiro lugar, que esses produtores de notícia - do repórter ao editor da primeira página vislumbrassem a política social como o que ela é: uma das modalidades das políticas públicas e que, portanto, envolve ações de governo que, em alguma medida, influenciarão o dia a dia do cidadão comum. Essa percepção é também o primeiro passo para o desenvolvimento da capacidade de diferenciar uma política governamental de cunho técnico e outra de cunho social. A reforma de uma estrada exige proposições e procedimentos muitíssimos diversos de uma política de combate à prostituição infantil, por exemplo. A primeira impõe a identificação de perigos específicos em determinados trechos rodoviários (o que vai gerar a demanda pelas obras de recuperação), o estabelecimento da extensão da reforma e os custos da intervenção, além de monitoramento e avaliação das obras implementadas. A segunda é uma outra história: embora também exija a identificação das causas do problema, o estabelecimento do universo a ser alterado (e como deve ser alterado), a estimativa

\footnotetext{
${ }^{4}$ Desde 1941 até 2009, foram realizadas no Brasil 104 conferências, nacionais e internacionais, sendo 68 entre 2003 e 2009. As informações estão disponíveis na página da Secretaria-Geral da Presidência da República: http:// www.presidencia.gov.br/estrutura_presidencia/sec_geral/
} 
de custos de uma intervenção, monitoramento e avaliação, é sabido que esse é um problema irremediavelmente mais complexo. Primeiro porque a prostituição infantil costuma ser ocasionada por mais de um fator e, portanto, tende a demandar mais de uma ação para ser eliminada. Além disso, envolve não só maior número de atores sociais (que precisam compreender a gravidade da situação para aderir a qualquer proposta destinada a revertê-la), mas também um número maior de instituições societárias e governamentais. Enfim, a área social envolve situações complexas, que abrigam conceitos muitas vezes subjetivos, além de interações intrincadas que marcam o cenário de disputa em torno das demandas colocadas para o poder público.

É neste sentido que autores como Sulbrandt e Rua ressaltam o fato de que, não raras vezes, os problemas sociais contemplados pelos mais diversos programas e projetos não podem ser "rigorosamente definidos" (SULBRANDT, 1994, p. 382). E, por isto mesmo, formular alternativas para a resolução dos problemas nesta área tende a ser tarefa árdua para os gestores públicos. Sem esta compreensão, portanto, é difícil encontrar, no campo das políticas sociais, a singularidade que dá contornos à notícia. Em outras palavras, fica difícil enxergar a pauta social - e mais difícil ainda inserir o cidadão comum nessa discussão. Ressalte-se que a importância da pauta social não mantém relação só com a relevância da democratização do debate em torno das mazelas sociais, mas, sobretudo, com a capacidade da mídia de perceber e acusar as razões pelas quais alguns problemas entram na agenda governamental e outros não.

Assim, discutir se a pauta social está ausente ou não da mídia ou se tem espaço adequado ou não, é uma questão que extrapola o debate sobre especialização. A escassez de repórteres especializados na área ou interesse de estruturar esta especialidade na redação é um sintoma, mas não oferece todas as perguntas. A simples definição de mais uma editoria sem se debruçar sobre questões mais amplas do jornalismo pode simplesmente significar mais uma segmentação de público e fragmentação de conteúdo. O avanço das políticas sociais nos cenários nacional e internacional e o aumento da mobilização social trazem indagações importantes para as redações. Esse fenômeno apresenta atores até então excluídos da agenda pública e que ganham visibilidade. Com isso, reforça a fórmula inaugurada em terras nacionais por João do Rio, mas também integra um esforço de repensar o jornalismo. Afinal, as mudanças de paradigma não acontecem sozinhas.

Como metodologia de análise será feito um retrospecto conceitual sobre a produção da notícia, quem aparece e como aparece, sem deixar de se refletir sobre quem produz e como produz a informação - a partir de um diagnóstico da mídia impressa, sob a ótica da pauta social e as possíveis rupturas neste sentido.

\section{Seleção e hierarquia da notícia}

Uma das primeiras questões é sobre como incorporar a temática de maneira adequada, já que uma cobertura de política pública não se enquadra, a princípio, no modelo tradicional de jornalismo. $\mathrm{O}$ que é notícia? Uma pergunta (aparentemente) simples, mas com respostas tão variadas quanto se pode imaginar. Logo, na lógica do jornalismo informativo, surgem as máximas, sempre simplificadoras, como "notícia não é quando o cachorro morde o homem, mas quando o homem morde o cachorro". Ou no cinismo importado do "good news, bad news".

Simplificadoras, porém escondem um princípio caro ao comércio de notícias, que é o do inusitado, principalmente se for bizarro. Mas tal princípio restringe o conceito de notícia e de jornalismo e, no máximo, fomenta a cultura cínica que alimenta o noticiário sensacionalista. Além do tradicional "cão de guarda" do poder, largamente difundido pelos manuais de redação e evocado por muitos para o livre exercício da profissão, há um aspecto cidadão que por muitas vezes vem sendo negligenciado, mas que pode ser um ponto nevrálgico neste necessário movimento de inflexão profissional.

A discussão sobre os critérios que regem o processo de produção da notícia é tão antiga quanto a profissão, mas a referência deste artigo reside principalmente na vasta literatura produzida pelo tema a partir de meados do século XX. Vasta, mas nem tão variada, considerando principalmente os enfoques técnicos desenvolvidos ao longo da tentativa de imprimir maior objetividade à atividade do jornalista. A discussão de valores se volta, desde o início, para discernir aspectos singulares que conferem aos fatos maior ou menor possibilidade 
de se tornarem notícias. Michael Kunckzik lembra que na Alemanha, a primeira dissertação sobre publicação de jornais, ainda de 1690, é de Tobias Peucer, que elabora uma extensa lista de tipos de assuntos que merecem publicação. "A quintessência do pensamento de Peucer é que o normal, o comum e o puramente privado carecem de valor como notícia." (KUNCKZIK, 2001, p. 242). Este autor identifica em Walter Lippman (Public Opinion, publicado em 1922) a referência da discussão contemporânea sobre o assunto. Ao trabalhar os valores informativos, ele menciona justamente "a clareza do fato, seu elemento de surpresa, sua proximidade geográfica, seu impacto e conflito pessoal" (idem). A discussão se notabiliza por tentar encontrar critérios para distinguir o notável da trivialidade. Embora estimulado por uma necessidade de imprimir mais objetividade à atividade jornalística, não é feito sem um grau considerável de subjetividade, porque

em última análise, os valores informativos nada mais são que as suposições intuitivas dos jornalistas com referência àquilo que interessa a um público determinado, àquilo que chama a sua atenção. (KUNCKZIK, 2001, p. 243).

Em 1950, David White desenvolveu a Teoria da Ação Pessoal, ou Teoria do Gatekeeper (WOLF, 1999). Em suas pesquisas, servindo-se de técnicas de observação do trabalho de editores, percebeu que quanto mais próximo do horário de fechamento do noticiário, mais subjetivas e arbitrárias são as decisões sobre o que publicar no jornal. Isto não é um fato a ser ignorado, mesmo considerando que o trabalho de White é muito unilateral, porque não trabalha com outros fatores que interferem na produção da notícia. Trabalhar os valores notícia do ponto de vista de escolha individual do profissional é desconhecer um processo mais complexo que envolve audiência, anunciantes, fontes e interesses da empresa jornalística.

Há que se considerar, ainda, mecanismos nem sempre sutis de controle desenvolvidos na própria estrutura do processo de produção da notícia e também na definição de padrões sociais e culturais da profissão. É o que mostra, por exemplo, o trabalho de Herbert Gans (citado por KUNCKZIK, 2001), feito em 1979 (Deciding What's News), no qual constata que "os jornalistas (estadunidenses) exerciam a autocensura em grande escala: tinham que combinar a própria avaliação de uma matéria jornalística com o que "pensavam que agradaria a seus editores" (KUNCKZIK, 2001, p. 272). No mesmo trabalho Gans identificou um noticiário não marcado pela novidade, mas por uma tendência à repetição, confirmação de status, reprodução de ordem social e de cristalização de estereótipos, reforçando um pensamento hegemônico:

A análise de Gans demonstrou que as notícias se concentravam no conhecido, e não no desconhecido, sendo que presidentes, candidatos à presidência e autoridades federais, estatais e locais recebiam grande parte da cobertura. Em geral, as pessoas comuns só apareciam nas notícias como protestadores, infratores ou vítimas. [...] Gans concluiu que ordem social equivalia a autoridade legítima. As notícias também sustentavam as noções de que a democracia é altruísta, o capitalismo é responsável e as tradições devem ser preservadas. Finalmente, a concentração em pessoas, e não em processos sociais, promovia o individualismo. (KUNCKZIK, 2001, p. 272-273).

Valer-se dos valores informativos como forma de captar a singularidade dos fatos e estruturar a atividade jornalística acaba por se tornar insuficiente. Funciona (ou não funciona) igual à manta muito curta que só vale para cobrir parcialmente os ombros em noite fria. De um lado, não consegue abarcar a complexidade dos fatos e fenômenos sociais porque se concentra demais no singular, sem abrir para as demais possibilidades, e também não assegura objetividade, muito embora possa ajudar a negar sua ausência.

Gans sugere a necessidade de se repensar a estrutura da produção da notícia e, segundo Kunckzik, ele "adota o ponto de vista de que a produção jornalística é demasiado importante para que seja deixada somente aos jornalistas" (idem, p. 274), apontando para a possibilidade de se produzir notícias a partir de "multiperspectivas", o que implicaria servir a outros segmentos da população para além da perspectiva oficial.

A introdução da pauta de políticas sociais integra-se a este movimento de refletir sobre os rumos do jornalismo, podendo reacender as discussões sobre as possibilidades de evidenciar uma função mobilizadora do jornalismo, sem neglicenciar o papel de exigir prestação de contas de governantes. Ao 
mesmo tempo, exatamente porque dão mais vida a essas funções, exige que seja repensado o formato das notícias. A notícia contextualizada informa o cidadão, municia-o de informações precisas, ajuda no processo de formação, afinal a contextualização não elimina o impacto da notícia, apenas a complementa.

\section{Quem aparece e como aparece}

Isto leva a um desdobramento importante das questões já levantadas: quem se vê no jornal? Talvez a mordida do cão não seja notícia porque "a dor da gente não sai no jornal", como diz a letra da música Notícia de Jornal, de Haroldo Barbosa e Luiz Reis. Esta é uma preocupação explícita na discussão sobre “jornalismo cívico" ou "jornalismo público". A adjetivação "público" ou "cívico" do jornalismo pode soar estranha. Mas o ponto de partida desta discussão é a tentativa de refletir e rever formas do jornalismo, apontando para a necessidade de se desenvolver uma agenda cidadã para o jornalismo. Ana María Miralles (2001) discute isto a partir de uma abordagem declaradamente questionadora dos valores liberais da informação, por considerá-los insuficientes.

Miralles e Gans se encontram na defesa de uma pauta marcada por "multiperspectivas". O que não implica, necessariamente, em uma negação do chamado jornalismo informativo. Mas requer um jornalismo informativo mais crítico e mais amplo. O jornalista é o analista do dia, do cotidiano, do seu tempo. Esta análise é feita a partir do que é singular. Mas o problema que se pode perceber a partir de leituras de trabalhos como os de Gans e de Miralles é o risco de fazer com que este traço se sobreponha de maneira a barrar as possibilidades de contexto dessa singularidade. É isso que leva ao sensacionalismo e, consequentemente, à desinformação. Rosa Nívea Pedroso (2001) identifica o problema:

A exarcebação do caráter singular da notícia superficializa e desvincula os fatos do contexto cultural, econômico e político que os origina. A abordagem apenas do caráter singular da realidade resulta num espaço discursivo que apresenta acontecimentos isolados e oportuniza a reificação de narrativas míticas e místicas acerca do destino do indivíduo.

Tal condição leva a uma situação que mais desinforma do que informa. Situação que levou Leão
Serva (2001) a descrever a mídia como uma "necrófila insaciável". Uma fórmula que mais distancia do que aproxima leitores ou potenciais leitores. Sobretudo quando a maioria desses leitores não consegue se ver no noticiário. Muito menos se localizar a partir dele. Ao relacionar desenvolvimento e imprensa livre, o economista Amartya Sen (citado por AVANCINI, s/d) destaca o papel da imprensa de dar proteção aos cidadãos. E isso implica ouvi-los e também dar voz. Significa que repensar a prática da produção da notícia é um caminho para reorientar possíveis funções da imprensa. Na proposta de aliar jornalismo e desenvolvimento, não será possível com a fórmula tradicional informativa descolada da discussão sobre a responsabilidade social da mídia.

Comunicação é um conceito de significado múltiplo e ambíguo e não pode se resumir à sua acepção de difundir informação (LIMA, 2004; HOLFELDT, 2001; MATTELART; MATTELART, 2000). Traz também, em sua etimologia, um conteúdo de compartilhamento de informação ${ }^{5}$. Nessa ponte de diálogo, outra indagação que chega via pauta social é o público. Isso está presente na questão acima. Mas também implica perguntar para quem fala o noticiário. Quem são os consumidores dessa informação e como chegar até eles? Jornalista fala com formador de opinião. Mas não só. A pergunta é se está conseguindo falar também com os beneficiários dos programas. Cumprir a missão de fiscalizar a execução dos programas não impede de continuar municiando o cidadão de informação, de prestar serviço e também de analisar, com clareza, o que está mudando na vida das pessoas.

Ana María Miralles (2001) reclama que não há uma agenda efetivamente pública que tenha capacidade de promover o intercâmbio dos muitos discursos que se produzem na sociedade. O que está definido, segundo a autora, é uma "agenda dos meios", estruturada em nome de uma Opinião Pública que, no fundo, é muito restrita e seria necessário ser ampliada:

O convite a reformular o conceito clássico de opinião pública torna possível a polifonia de vozes e inclui os processos argumentativos e dialógicos

\footnotetext{
5 A etimologia da palavra "comunicação", segundo consta no dicionário Houaiss, vem do latim communicatio,ónis 'ação de comunicar, de partilhar, de dividir'. Lista 29 acepções do termo, de rubricas diferentes e derivadas. A maioria trabalha com o conceito de transmissão.
} 
[...] um papel que ultrapassa as páginas de opinião e dos chamados líderes de opinião. (MIRALLES, 2001, p. 47).

A reivindicação de uma imprensa mais polifônica remete à necessidade de repensar fontes de informação, analisar contextos informativos diferentes. Inclui um olhar mais atento para observar as mudanças do cotidiano das pessoas, como já mencionado, e o que elas têm a dizer sobre isso. É uma postura que se atrela ao debate da responsabilidade social da imprensa. Mas não deixa de ter um viés também econômico, porque é importante até para entender o ouvinte, telespectador ou leitor. Os estudos de institutos de pesquisa, como o Instituto de Pesquisa Econômica Aplicada (Ipea) e a Fundação Getúlio Vargas (FGV), dão conta de uma ascendente classe $\mathrm{C}$, que está engrossando o rol de consumidores, inclusive consumidores de notícias, acrescentando ainda a classe $\mathrm{D}$, como pode ser exemplificado pelos últimos dados do IVC (Instituto Verificador de Circulação) que aponta o jornal popular Super Notícia como primeiro colocado nas vendas em 2010, ao mesmo tempo que mostra o crescimento de outros jornais, como o Extra e o Meia Hora, do Rio de Janeiro, e o Diário Gaúcho, do Rio Grande do Sul.

\section{Quem produz e como produz}

Como este artigo não tem o propósito de deslindar os inúmeros aspectos da formação do jornalista, mas sim levantar alguns aspectos que dificultam a presença da questão social nos veículos de comunicação, é possível apontar ao menos duas questões pertinentes ao papel do jornalista neste processo. A primeira refere-se à reconfiguração do sujeito na sociedade contemporânea e a segunda levanta a questão do outro e da representação no processo de produção da informação.

A noção antropocêntrica oriunda do Renascentismo - em que a busca pela essência do sujeito era o centro -, passa por reconfigurações sucessivas que alteram o lugar do sujeito no interior da sociedade. Mudanças no espaço, no tempo, nos laços de sociabilidade, na forma de pensar deslocam o indivíduo, agora no século XXI, para uma situação em que o efêmero torna-se o constante, o recorrente. A visão de um sujeito enredado pelas amarras das estruturas, ou mais propriamente, como pensava Pierre
Bourdieu (2006), pelo habitus, não conduzem mais o indivíduo em sua atuação cotidiana.

Nessa nova modernidade líquida (BAUMAN, 2001), a discussão sobre a identidade expressa tanto uma necessidade, esta com o intuito de se "situar" na sociedade, quanto uma busca por um lastro, um sentimento de pertencimento a algum grupo ou modo de relação afetiva ou até mesmo profissional, mesmo que este "sentimento" seja alterado de tempos em tempos.

O sujeito jornalista, como todo ser humano, não se encontra completamente isolado em seu espaço de trabalho. Por mais que o nomadismo seja uma constante na sociedade contemporânea (MAFESOLI, 2001), persiste ainda uma relativa necessidade de identificação, o que não significa que esta tenha a duração e a intensidade de outrora. Estes laços mais fluidos, entretanto, esgarçam as relações que o jornalista como mediador privilegiado da sociedade poderia estabelecer na sociedade, dado que o ser humano vê e é sempre visto pelo outro, como bem argumenta Roger Silverstone:

\footnotetext{
Tudo o que fazemos, tudo o que somos, como sujeitos e atores no mundo social, dependem de nossa relação com os outros: de como os vemos, os conhecemos, nos relacionamos com eles, nos importamos com eles ou os ignoramos. Vê-los é crucial [...]. O Outro, no entanto, pode agir como um espelho; e, no reconhecimento da diferença, construímos nossa própria identidade, nosso próprio senso de nós mesmos, no mundo. Se compreendemos essas diferenças, ou mesmo se meramente as vemos, então temos de levar o Outro em conta. (SILVERSTONE, 2005, p. 249).
}

Nesse sentido, vale observar como são produzidas as matérias na atualidade. As novas tecnologias proporcionam relativo conforto para os profissionais que podem, agora, ter acesso às informações sem deslocamentos, como já comentado na introdução. Uma pesquisa realizada por Nick Davies (2008) na Inglaterra mostra que das 2.000 notícias avaliadas somente $12 \%$ foram produzidas por intermédio da apuração. Nick Davies, além de verificar a origem das informações veiculadas, acompanhou o trabalho cotidiano dos jornalistas em algumas redações e percebeu que o contato face a face está reduzindo a capacidade do profissional de praticar um jornalismo com mais qualidade: "nós parecemos estar engajados na produção em massa da ignorância por causa 
das corporações e as 'estatísticas' que nos saturam tem [...] nos mantido em nossas mesas, então geralmente nós simplesmente perdemos a capacidade de sair e fazer contatos". 6

Então, na medida em que este outro não aparece, a não ser em números ou declarações formais, a própria capacidade de apuração pode ficar reduzida à busca de números e declarações formais, entretanto esta lógica nem sempre se repete e inúmeros exemplos mostram que é possível rompê-la, como no seguinte caso. Em 2006, durante um seminário do Banco Mundial em Belo Horizonte, o repórter Rafael Sânzio subiu o morro para fazer a matéria de capa do caderno de Economia do jornal local Hoje em Dia sobre a abertura do evento. Estava em pauta um empréstimo do Banco para o Programa Bolsa Família. O mesmo Banco que estava movimentando a região onde acontecia o evento, inclusive na vila do entorno. Foi lá que ele foi procurar saber como viviam as famílias que recebiam o dinheiro do programa financiado pelo Banco. Este exemplo, entre muitos outros que poderiam ser citados, revela que são inúmeras as possibilidades de renovar a cobertura, de acompanhar as mudanças, de revigorar o jornalismo.

\section{Considerações finais}

Importante estudar a mídia dada a sua centralidade na sociedade hoje. A Academia precisa refletir sobre o tema, apresentar diagnósticos e sugestões, rompendo fronteiras. Afinal, o jornalismo brasileiro, dentro da lógica da base capitalista que o organiza, tem forte apelo mercantil e trabalha em torno da noção de mercadoria, mas não se resume a este aspecto. Traz também as contradições decorrentes do fato de estar igualmente inserido em contexto social e político numa relação interdependente do sistema político, o que tem significativas implicações para o debate democrático. Nesse conflito, é possível identificar brechas que, bem utilizadas pelos profissionais da área, podem contribuir para a democratização da informação, para a humanização das narrativas, ampliando assim a polifonia do campo.

Discutir a dimensão política e ainda social do processo de produção da informação significa descartar a noção de mero fator de transmissão do real que muitos ainda advogam, o que significa reconhecer seu papel político, o que implica, ainda, aceitar a transmissão da informação como insuficiente para pensar o papel da imprensa: precisamos pensar no jornalismo como espaço de comunicação, de modo a estabelecer mecanismos mais dialogais dentro do próprio processo de produção da notícia.

Nesse sentido, vale destacar importantes iniciativas que buscam resgatar essa dimensão do jornalismo, que estão explorando com rigor o potencial crítico da área. Isso acontece, por exemplo, a partir da implementação de novas mídias - blogs e sites que se dedicam a observar, criticar e analisar o jornalismo, além de oferecer contraponto à cobertura da mídia convencional. Uma experiência de destaque, que tem surtido efeito no próprio processo de reflexão sobre o papel da mídia como um todo, vem da Agência de Notícias dos Direitos da Infância (Andi), por meio do Programa de Cooperação para Qualificação de Estudantes de Jornalismo, conhecido por InFormação, realizado com apoio do Fórum Nacional de Professores de Jornalismo e com adesão de várias universidades brasileiras.

Esse esforço requer que profissionais, professores e pesquisadores da área repensem muitos conceitos, alguns tidos como já cristalizados. Talvez seja o caso de pensar se a cristalização de alguns conceitos não esteja corroendo alguns princípios fundamentais do jornalismo, como é o caso da crítica. A técnica tem de servir para a ampliação dos horizontes, nunca para encurtá-los. É preciso verificar até que ponto um conceito muito rígido de notícia não permite enxergar além. Sabe-se, ainda, que muito dos "pecados" da imprensa vêm da excessiva mercantilização da notícia. Ninguém nega a origem econômica da atividade. Muito menos que a notícia seja também posta a venda. Mas não é um "produto" como qualquer outro. Ainda que o fosse, o jornalismo não estaria livre de responder pelas responsabilidades sociais das atividades que o constituem, tampouco do seu poder de abrir novos caminhos para a participação dos cidadãos nos assuntos de governo e para o incentivo ao debate público, de maneira a contribuir para a ampliação e incremento dos direitos sociais.

\footnotetext{
${ }_{6}$ Disponível em http://www.pressgazette.co.uk/story.asp?sectioncode=1\& storycode $=40117$. (Tradução das autoras)
} 


\section{REFERÊNCIAS}

AVANCINI, Marta. Políticas Públicas na pauta dos estudantes de jornalismo. In: FORMAÇÃO: Programa de Cooperação para qualificação de estudantes de jornalismo. Agência de Notícias dos Direitos da Infância. Disponível em: <http:// informacao.andi.org.br/relAcademicas/site/reportagem.pdf $>$ Acesso em: set 2010.

BAUMAN, Zygmund. Modernidade líquida. Rio de Janeiro: Zahar, 2001.

BOURDIEU, Pierre. A ilusão biográfica. In: AMADO, Janaína; FERREIRA, Marieta de Morais (Orgs.). Usos \& abusos da história oral. Rio de Janeiro: FGV, 2006.

DAVIES, Nick. Churnalism has taken the place of what we should be doing: telling the truth. Disponível em:

http://www.pressgazette.co.uk/story.asp?sectioncode=1\&sto rycode $=40117$. Acesso em: $\operatorname{mar} 2008$.

HOLFELDT, Antonio; MARTINO, Luiz C.; FRANÇA, Vera V. (Orgs.). Teorias da comunicação: conceitos, escolas e tendências. Petrópolis, RJ: Vozes, 2001.

IPEA. Brasil: o estado de uma nação. Rio de Janeiro: IPEA, 2005

KUNCZIK, Michael. Conceitos de jornalismo: norte e sul. São Paulo: Edusp, 2001.

LAGE, Nilson. Linguagem jornalística. São Paulo: Ática, 2001. Cap. 1

LIMA, Venício A. de. Mídia: teoria e política. São Paulo: Editora Fundação Perseu Abramo, 2004.

MAFFESOLI, Michel. Sobre o nomadismo: vagabundagens pós-modernas. Rio de Janeiro: Record, 2001.

MAIA, Marta R. The rule of transparency: as an element of democratization in the journalism production process. Brazilian Journalism Research, v.4, n.2, Semester 2, 2008.

MATTELART, Armand; MATTELART, Michéle. História das teorias da comunicação. 3.ed. São Paulo : Loyola, 2000 .

MEDINA, Cremilda. Notícia: um produto à venda. Jornalismo na sociedade urbana e industrial. São Paulo: Alfa Omega, 1978.

MIRALleS, Ana María. Periodismo, opinión pública y agenda ciudadana. Bogotá: Grupo Editorial Norma, 2001.

PEDROSO, Rosa Nívea. Contribuições aos estudos do sensacionalismo no jornalismo impresso brasileiro. Sala de Prensa, ano 3, v. 2, set., 2001. Disponivel em: <www. saladeprensa.org/art264.htm>

RUA, Maria das Graças. Análise de políticas públicas: conceitos básicos. In: ; CARVALHO, Maria I. V. O estudo da política: tópicos selecionados. Brasília: Paralelo
15, 1998a. p. 231-260.

SANTOS, Milton. Por uma outra globalização: do pensamento único à consciência universal. São Paulo: Record, 2004.

SERVA, Leão. Jornalismo e desinformação. São Paulo: Editora Senac, 2001.

SODRÉ, Nelson Werneck. História da imprensa no Brasil. Rio de Janeiro: Mauad, 1999. p. 251-390.

SULBRANDT, José. A avaliação dos programas sociais: uma perspectiva crítica dos modelos usuais. In: KLIKSBERG, Bernardo (Org.). Pobreza: uma questão inadiável - novas propostas a nível mundial. Brasília : ENAP, 1994. p. 365-408

WAINER, Samuel. Minha razão de viver: memórias de um repórter. Rio de Janeiro: Record, 1988. 282 p.

WOLF, Mauro. Teorias da comunicação. Lisboa: Editorial Presença, 1999. 